\title{
SISTEM MONITORING AKUARIUM BERBASIS MIKROKONTROLER DAN DJANGO WEB FRAMEWORK
}

\author{
Muhamad Nasir ${ }^{1}$, Novia Natasya ${ }^{2}$ \\ ${ }^{1,2}$ Politeknik Negeri Bengkalis, Bengkalis, Riau, Indonesia \\ ${ }^{1}$ nasirapolbeng.ac.id \\ ${ }^{2}$ novianatasya. 2298@gmail. com
}

\begin{abstract}
Currently aquarium monitoring is still done manually, that is still monitored by having to look directly at the aquarium continuously. If the monitoring system is replaced by using a more modern system it will greatly facilitate the fish keepers themselves. One of the systems proposed to overcome these problems is the realtime aquarium monitoring system base on microcontroller. This system uses turbidity sensors, ultrasonic sensors, pH sensors and LM35 sensors that function to measure water turbidity, water level, water acidity and also water temperature connected to the website to monitor the aquarium. This system makes it easy for fish keepers to monitor the aquarium without having to look at the aquarium directly. The System is created using the django base python and SQLite framework as its database. This system was tested at Bengkalis State Polytechnic, using a mini aquarium. This research succeeded well by displaying data on the level of turbidity of water, water level, water acidity and water temperature. The data obtained is displayed on the website in the form of graphics and numbers.
\end{abstract}

Keywords—Monitoring System, Aquarium, Realtime, website.

Intisari-Saat ini pemantauan akuarium masih dilakukan secara manual yakni masih dipantau dengan cara harus melihat langsung secara terus menerus di akuarium. Jika sistem pemantauan tersebut digantikan dengan menggunakan sistem yang lebih modern akan sangat memudahkan para pemelihara ikan itu sendiri. Salah satu sistem yang diusulkan untuk mengatasi permasalahan tersebut adalah Sistem monitoring akuarium secara realtime berbasis mikrokontroler. Sistem ini menggunakan sensor turbidity, sensor ultrasonik, sensor pH dan sensor LM35 yang berfungsi untuk mengukur tingkat kekeruhan air, ketinggian air, keasaman air dan juga suhu air yang terhubung dengan website monitoring akuarium. Sistem ini memudahkan untuk pemelihara ikan dalam memonitoring akuarium tanpa harus melihat akuarium secara langsung. Sistem yang dibuat menggunakan framework django base python dan SQLite sebagai databasenya. Sistem ini diuji di Politeknik Negeri Bengkalis, menggunakan akuarium mini. Sistem ini berhasil dengan baik dengan menampilkan data tingkat kekeruhan air, ketinggian air, keasaman air dan juga suhu air. Data yang didapatkan ditampilkan di website dalam bentuk grafik dan angka.

Kata Kunci-Sistem Monitoring, Akuarium, Realtime, website, Django Framework.

\section{PENDAhuluan}

Penggunaan air untuk ikan pada akuarium, harus selalu dijaga tingkat kekeruhan dan ketinggian airnya.
Dampak air yang keruh dapat menyebabkan terganggunya fisik ikan tersebut bahkan kematian. Terlebih pada ikan tertentu seperti ikan air tawar, dimana pada jenis ikan tersebut harus dijaga tingkat kekeruhan dan ketinggian airnya agar tidak mempengaruhi kehidupan dari ikan tersebut. Selain itu, kondisi temperatur dan $\mathrm{pH}$ air dalam akuarium harus dijaga karena apabila temperatur melebihi batas ideal yang telah ditentukan dapat mempengaruhi metabolisme ikan dan juga organisme lainnya begitupun dengan $\mathrm{pH}$ air nya[1],[2],[3],[4].

Pemantauan akuarium saat ini masih dilakukan dengan cara manual, dalam arti kata masih dipantau secara langsung dalam waktu berkala. Banyak orang yang hobi memelihara ikan kebingungan jika mereka bepergian jauh dengan jangka waktu yang lama pasti nantinya akan menimbulkan keresahan terhadap akuarium yang akan ditinggalkan. Hal ini dimungkinkan karena tidak ada yang memelihara ikannya dengan baik. Dengan permasalahan diatas, maka diusulkan sistem untuk membantu menyelesaikan masalah yang terjadi dengan membuat sistem monitoring akuarium berbasis mikrokontroler dan django web framework.

Sistem monitoring akuarium ini diharapkan dapat membantu para pemelihara ikan dalam memantau ikanikan yang ada pada akuarium. Tingkat kekeruhan air pada akuarium diukur menggunakan sensor turbidity, begitu juga dengan ketinggian air yang diukur menggunakan sensor ultrasonik dan $\mathrm{pH}$ air menggunakan sensor $\mathrm{pH}$, serta suhu air yang diukur menggunakan sensor LM35 yang dipasang pada akuarium. Hasil dari pengukuran sensor-sensor yang dipasang akan ditampilkan melalui website yang bisa dimonitoring oleh para pemelihara ikan.

\section{LANDASAN TEORI}

\section{A. Arduino Uno}

Arduino adalah sistem purnarupa elektronika (electronic prototyping platform) berbasis open-source yang fleksibel dan mudah digunakan baik dari sisi perangkat keras/hardware maupun perangkat lunak/software. Di luar itu, kekuatan utama arduino adalah jumlah pemakai yang sangat banyak sehingga tersedia pustaka kode program (code library) maupun modul pendukung (hardware support modules) dalam jumlah yang sangat banyak. Hal ini memudahkan para pemula untuk mengenal dunia mikrokontroler. Arduino sendiri adalah rangkaian elektronik open source yang didalamnya dilengkapi dengan sebuah chip 
mikrokontroler sebagai kompunen utama. Perangkat kerasnya memiliki prosesor Atmel AVR dan perangkat lunaknya memiliki Bahasa pemrograman sendiri $[1][2][3]$.

\section{B. Sensor Turbidity}

Sensor turbidity merupakan sensor mengukur tingkat kekeruhan air yang dapat dengan mudah dikombinasikan dengan arduino. Sensor turbidity dapat disebut juga sebagai salah satu komponen yang berfungsi sebagai detektor cahaya yang dapat mengubah efek cahaya menjadi sinyal listrik [5],[6].

\section{Sensor Ultrasonik}

Sensor ultrasonik adalah sensor yang memanfaatkan prinsip gelombang ultrasonik. Gelombang ultrasonik merupakan gelombang akustik yang memiliki frekuensi mulai $20 \mathrm{kHz}$ hingga sekitar $20 \mathrm{MHz}$. Alat ini dapat digunakan untuk mengukur jarak benda dari $2 \mathrm{~cm}-4 \mathrm{~m}$ dengan akurasi $3 \mathrm{~mm}$. Alat ini memiliki 4 pin, pin Vcc, Gnd, Trigger, dan Echo. Pin Vcc untuk listrik positif dan Gnd untuk ground-nya. Pin Trigger untuk trigger keluarnya sinyal dari sensor dan pin Echo untuk menangkap sinyal pantul dari benda. Sensor ini digunakan untuk mengukur tingkat ketinggian air pada sistem monitoring yang akan dibuat [7],[8].

\section{Sensor $\mathrm{pH}$ Meter}

Fungsi pH Meter adalah untuk mengukur pH (kadar keasaman atau basa) suatu cairan. Sebuah $\mathrm{pH}$ meter terdiri dari sebuah elektroda (probe pengukur) yang terhubung ke sebuah alat elektronik yang mengukur dan menampilkan nilai $\mathrm{pH}[1],[2]$.

\section{E. Sensor LM35}

Sensor suhu LM35 adalah komponen elektronika yang memiliki fungsi untuk mengubah besaran suhu menjadi besaran listrik dalam bentuk tegangan. Sensor Suhu LM35 yang dipakai dalam penelitian ini berupa komponen elektronika elektronika yang diproduksi oleh National Semiconductor [2][9].

\section{F. Resistor}

Resistor adalah komponen elektronika yang banyak kita lihat pada komponen elektronik umumnya, komponen elektronika pasif ini bisa kita lihat jumpai pada mesin elektronik seperti televisi, radio dan masih banyak lainnya. Sebagaimana fungsi resistor yang sesuai namanya bersifat resistif dan termasuk salah satu komponen elektronika dalam kategori komponen pasif.

\section{G. Arduino IDE}

IDE merupakan singkatan dari Integreted Developtment Enviroenment, atau secara bahasa mudahnya merupakan lingkungan terintegrasi yang digunakan untuk melakukan pengembangan. Disebut sebagai lingkungan karena melalui software inilah arduino dilakukan pemrograman untuk melakukan fungsifungsi yang dibenamkan melalui sintaks pemrograman. Arduino menggunakan bahasa pemrograman sendiri yang menyerupai bahasa $\mathrm{C}$ [1],[5].

\section{H. SQLite}

SQLite adalah sebuah engine database $S Q L$ yang langsung tertanam atau pada aplikasi. Tidak seperti kebanyakan database $S Q L$ lainnya, SQLite tidak memiliki server yang terpisah dari aplikasi. SQLite telah didukung oleh banyak bahasa pemrograman seperti C, C ++, BASIC, C \#, Python, Java dan Delphi [10].

\section{JavaScript Object Notation (JSON)}

JavaScript Object Notation adalah suatu format ringkas pertukaran data komputer. Formatnya berbasis teks dan terbaca oleh manusia. serta digunakan untuk merepresentasikan struktur data sederhana dan larik asosiatif. Format JSON sering digunakan untuk mentransmisikan data terstruktur melalui suatu koneksi jaringan pada suatu proses yang disebut serialisasi. Walaupun JSON didasarkan pada subset bahasa pemrograman JavaScript, JSON dianggap sebagai format data yang tak tergantung pada suatu bahasa.

\section{J. DBeaver}

DBeaver adalah aplikasi untuk manajemen database dengan mode GUI (graphical). DBeaver sendiri selain menyediakan versi berbayar, juga menyediakan Community Edition yang open source.

\section{K. Django}

Django adalah sebuah framework full-stack untuk membuat aplikasi web dengan bahasa pemrograman python. Framework akan membantu kita membuat web lebih cepat, dibandingkan menulis kode dari nol [10].

\section{METODE PENELITIAN}

\section{A. Alat Penelitian}

Alat yang digunakan dalam penelitian ini adalah sebagai berikut :

1. Perangkat Keras (Hardware)
a. Laptop
b. Arduino Uno
c. Sensor Turbidity
d. Sensor Ultrasonik
e. Sensor $\mathrm{pH}$ meter
f. Sensor LM35
g. Kabel USB / Kabel Data
h. Kabel Jumper

2. Perangkat Lunak (software)
a. Arduino IDE
b. Dbeaver
c. Visual Studio Code

B. Rancangan Desain Sistem Secara Umum

Pada bagian ini diuraikan perancangan sistem secara umum dan ditampilkan semua peralatan yang dibutuhkan untuk membuat sistem monitoring akuarium secara realtime sekaligus rancangan alur kerja dari sensor-sensor tersebut. Rancangan ini berguna untuk mempermudah dalam mengetahui bagaimana alur kerja sistem secara garis besar. Adapun desain sistem secara umum yang membahas alur kerja sistem dapat dilihat pada Gambar 1. 
Berdasarkan Gambar 1, pada penelitian ini dirancang sistem monitoring akuarium yang menggunakan sensor turbidity, sensor ultrasonik, sensor $\mathrm{pH}$ dan sensor LM35 untuk mengukur kondisi air dan suhu air pada akuarium. Semua sensor dihubungkan ke arduino uno.

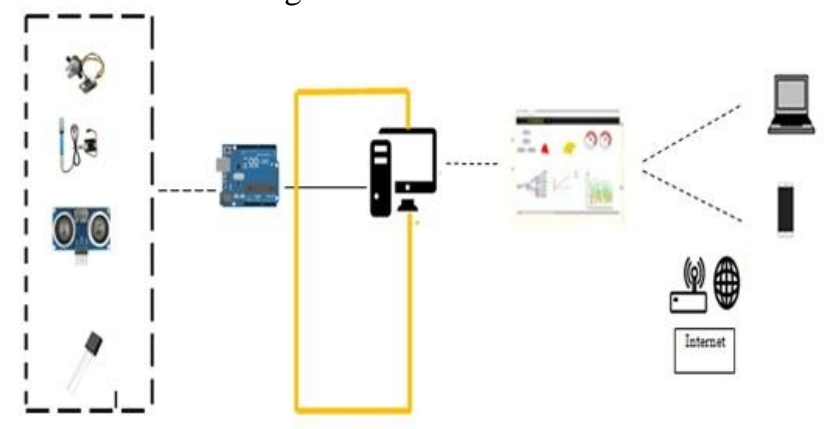

Gambar 1. Rancangan Desain Sistem Secara Umum

Pada arduino terdapat perintah program untuk mengukur tingkat kekeruhan, ketinggian, keasaman dan suhu air pada akuarium. Arduino dihubungkan ke laptop melalui kabel USB, kemudian data yang terbaca tersebut dikirim ke server dan semua data sensor dari server tersimpan di database, lalu hasil dari nilai kekeruhan, ketinggian, keasaman dan suhu air pada akuarium tersebut ditampilkan pada di website berupa grafik dan angka.

1. Perancangan Sistem Perangkat Keras dan Perangkat Lunak

Sistem yang dirancang memiliki fungsi untuk mengukur kondisi air menggunakan sensor turbidity, ultrasonik, $\mathrm{pH}$ air dan suhu yang dikoneksikan dengan mikrokontroler arduino uno dan dan laptop sebagai server.

Arduino berfungsi sebagai media yang mengatur pengkodean pada sensor turbidity, ultrasonik, $\mathrm{pH}$ dan LM35 untuk membaca nilai untuk kondisi dan suhu air pada akuarium, laptop yang tersambung melalui kabel USB pada Arduino akan mengambil nilai untuk kondisi dan suhu air pada akuarium tersebut dan disimpan dalam database kemudian ditampilkan pada website dan berbentuk grafik dan angka.

2. Rancangan Diagram Alir Sistem

Adapun rancangan secara umum diagram alir dari sistem yang dirancang untuk sistem monitoring akuarium secara realtime terdapat pada flowchart pada Gambar 2.

Pada Gambar 2 dijelaskan bahwa proses awal dimulai sampai dengan proses akhir. proses awal dimulai dengan pemasangan semua sensor yaitu sensor turbidity, sensor ultrasonik, sensor pH dan sensor LM35 pada arduino. Selanjutnya, sensor akan dicek apakah bekerja dengan baik atau tidak. Kemudian, data sensor yang didapat akan dikirim ke server dan tersimpan di database. Data yang tersimpan akan ditampilkan pada website dengan tampilan data grafik dan angka.

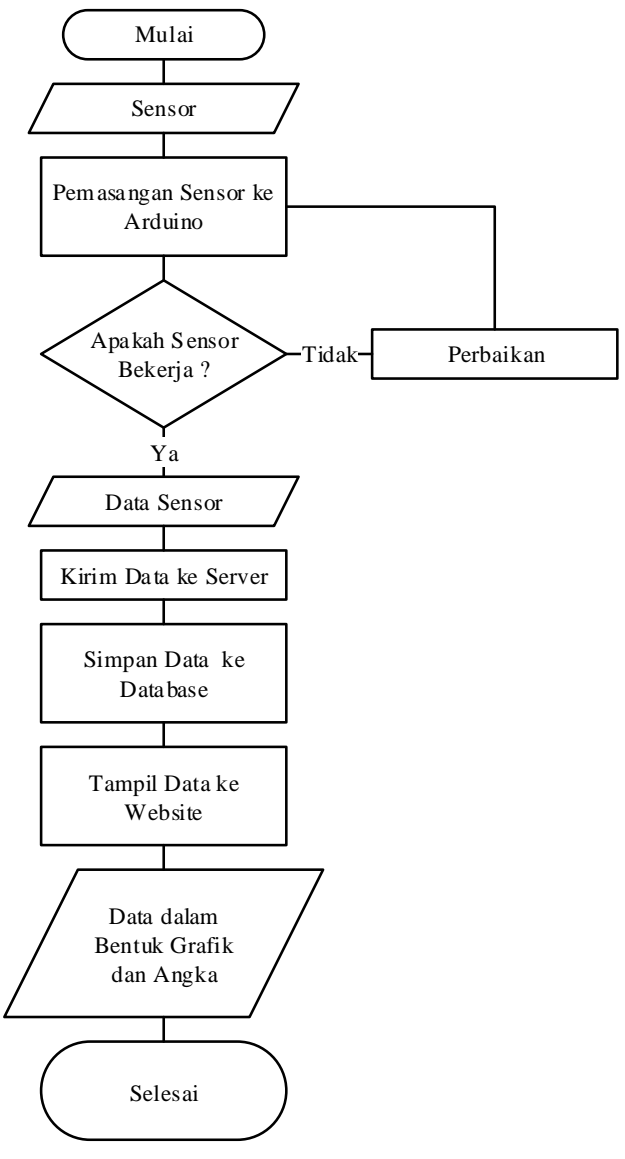

Gambar 2. Flowchart Sistem

\section{HASIL DAN PEMBAHASAN}

Penelitian ini menghasilkan sistem monitoring akuarium secara realtime untuk mengetahui kondisi dan suhu air. Sistem ini memberikan informasi data tingkat kekeruhan air, ketinggian air, keasaman dan suhu air pada akuarium yang diukur menggunakan sensor turbidity, ultrasonik, pH dan LM35 yang bisa diakses melalui website. Data-data kondisi dan suhu air pada akuarium yang diukur oleh sensor-sensor tersebut tersimpan pada database dan ditampilkan pada website yang telah dibuat. Informasi yang ditampilkan berupa nilai dari semua sensor pada akuarium dan juga keterangan suhu secara realtime.

Adapun hasil secara umum berupa sistem monitoring akuarium melalui website yang telah dibuat yang dinyatakan pada Gambar 3 dan Gambar 4 . Website monitoring akuarium merupakan website yang bertindak sebagai penampil data sensor turbidity, ultrasonik, pH dan LM35 yang diambil dari database SQLite. 


\section{IOT Manage( Server )}

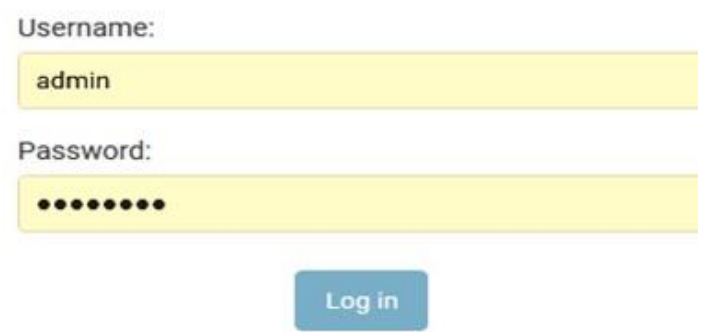

Gambar 3. Tampilan Login

Gambar 3 merupakan halaman awal website untuk melihat tampilan data sensor. Pengguna harus login terlebih dahulu untuk melihat data sensor yang berupa grafik dan angka.

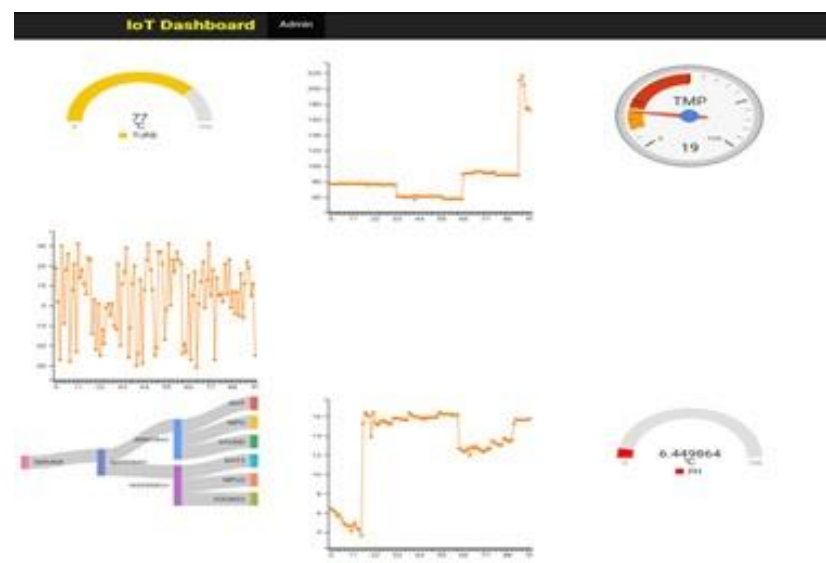

Gambar 4. Tampilan grafik data sensor

Gambar 4 menampilkan semua data sensor yang terpasang pada arduino. Data sensor yang ditampilkan berupa grafik dan angka. Data sensor yang ditampilkan yaitu data sensor turbidity, data sensor ultrasonik, data sensor $\mathrm{pH}$ dan data sensor LM35.

Tabel 1.

Hasil pengujian

\begin{tabular}{|l|l|c|c|}
\hline No & Jenis Sensor & $\begin{array}{c}\text { Hasil Pengujian } \\
\text { Menampilkan Data } \\
\text { Sensor }\end{array}$ & $\begin{array}{c}\text { Hasil } \\
\text { Pengujian } \\
\text { Website }\end{array}$ \\
\hline 1. & Turbidity & Berhasil & Berhasil \\
\hline 2. & Ultrasonik & Berhasil & Berhasil \\
\hline 3. & PH & Berhasil & Berhasil \\
\hline 4. & LM35 & Berhasil & Berhasil \\
\hline
\end{tabular}

\section{KESIMPULAN}

Berdasarkan hasil pengujian sistem monitoring akuarium, dapat diambil kesimpulan yaitu sistem ini dapat menampilkan data secara realtime berbasis mikrokontroler, dan data dapat ditampilkan dalam bentuk grafik dan angka. Sensor turbidity, sensor ultrasonik, sensor $\mathrm{pH}$ dan sensor LM35 yang digunakan berhasil dengan baik menampilkan data di website. Data yang ditampilkan yaitu data tingkat kekeruhan air, data ketinggian air, data keasaman air, dan juga data suhu air. Pemelihara dapat memantau kondisi akuarium dari jarak jauh. Setelah dilakukan pengujian sistem menggunakan web browser, didapati bahwa website berhasil dengan baik dan menampilkan tampilan yang responsive. Data tiap sensor berhasil tampil dengan baik dalam bentuk grafik dan angka.

\section{REFERENSI}

[1] Eltra, E, B., dkk., Otomatisasi Sistem Kontrol Ph dan Informasi Suhu Pada Akuarium Menggunakan Arduino Uno Dan Raspberry Pi 3 : Kupang, 2018.

[2] Rivai, M., "Sistem Monitoring PH dan Suhu Air dengan Transmisi Data Nirkabel", Surabaya : Institut Teknologi Sepuluh Nopember, 2017.

[3] S. Charana, " Arduino Based Aquarium Monitoring System", International Research Journal of Engineering, vol.06, pp.605-608, 2019

[4] M. S. U. Chowdury, "IoT Based Real-time River Water Quality Monitoring System, Procedia Computer Science 155, pp.161-168, 2019

[5] M. S. Ramadhan, "Sistem Kontrol Tingkat Kekeruhan Kekeruhan pada Aquarum Menggunakan Arduino Uno", J. Tek. ITS, vol.7, pp.87-91, 2018

[6] Simanjuntak , D, A., Sistem Monitoring Kekeruhan Dengan Metode Pendeteksi Warna Pada Air Dengan Sms Gateway : Sumatera Utara, 2016.

[7] Tenggono, A., Wijaya, T., Sistem Monitoring Dan Peringatan Ketinggian Air Berbasis Web Dan Sms Gateway : STMIK Pontianak, 2015

[8] Sadi, S., Rancang Bangun Monitoring Ketinggian Air Dan Sistem Kontrol Pada Pintu Air Berbasis Arduino Dan Sms Gateway : Palembang, 2018.

[9] Siswanto., Adiguna, A., Monitoring suhu Dan Ketinggian air Aquarium Dengan Sensor Ds18b20, Hcsr04 Dan Mikrokontroler Arduino Uno R3 Berbasis Web: Jakarta, 2018.

[10] D. P. Jose, "IoT Based Water Management using HC-12 and Django", International Conference on Data Science and Communication (IconDSC), 2019 